\title{
'SO I DECIDED NOT TO INVADE STRAIGHT BLACK MEN'S SPACE': EXPLORING HETERONORMATIVE SPACES ON CAMPUS
}

\author{
P. Kiguwa* \\ Psychology Department \\ e-mail: Peace.Kiguwa@wits.ac.za
}

\section{Langa*}

e-mail: Malose.Langa@wits.ac.za

*Psychology Department

Wits University

Johannesburg, South Africa

\section{ABSTRACT}

Challenging heteronormative spaces has been identified as one of the key difficulties facing the issue of destabilisation of deeply entrenched gendered and sexual practices and spaces within institutional contexts. In a university context, that includes a hegemonic masculine student residence culture; this may be even more challenging and disrupting to how one mediates social and academic space. Challenging includes awareness of how one may be able to challenge, as well as moments when one is not able to challenge. Strategies of resistance may be adopted that further reinforce gay male students' participation in academic space. Through qualitative analysis of a group of gay male students living in residence at a South African university, we explore these students' movement through different spaces on campus within the residences. Using performative theory and the concept of hegemonic masculinity, the findings highlight sexuality's intersection with other identities both in the experience of and resistance to victimisation.

Keywords: Gay black students, student residence, university, sexuality, heteronormativity, hegemonic masculinity, performative theory.

\section{INTRODUCTION}

Challenging heteronormative social spaces within institutions of higher learning has been argued to be one of the key aspects of institutional transformation for many lesbian, gay, bisexual, transgendered (LGBT) and other non-gender conforming students in higher education (Msibi 2013). Inclusivity for many LGBT-identified students remains an elusive practice (Nduna and Mavhandu-Mudzusi 2015), despite the existing university policies to promote nondiscrimination on the basis of sexual orientation. Elsewhere, research shows that issues of diversity and inclusivity for many LGBTI students on university campus remains a problem 
and that many of these students do not consider spaces within the university campus to be safe spaces (Ellis 2009; Taulke-Johnson 2008). Recent research conducted in South Africa demonstrates that university residences remain one of the most homophobic spaces and are deeply entrenched in heteronormative cultures that exclude LGBTI students (Jagessar and Msibi 2015). Given these issues facing inclusion and transformation within the university, it is important to consider how LGBTI students are not only facing being on campus but also to consider the different kinds of strategic responses to these moments and practices of exclusion. This article contributes to the ongoing discussion on transforming university spaces by focusing on the subjective experiences of gay male students within the university residences. The article discusses the different moments of exclusion faced by these students as well as the different meanings attached to identity performances of being a gay and what the different implications for resistance adopted by these students tell us about the possibility for challenging heteronormative space more generally. Clearly, much work remains to be done in this area, that not only aims to produce research on students' attitudes toward LGBTI persons but also understanding the significance of social spaces for LGBTI students and how institutions of higher learning may work toward transformation for all students.

We argue that homophobia within university spaces must read within a gendered lens that accounts for the specifically gendered form that homophobia takes. In other words, homophobia within male student spaces is characterised not only by explicit prejudices and bias with regards to sexual orientation, but also, is informed by broader patriarchal and gendered influences. This means that many gay male students will experience homophobia differently and sometimes significantly worse than other gender non-conforming students. This is not to argue that these other experiences are lesser in significance, but rather to point to the intersections of heteronormativity, with particular emphasis on hegemonic masculinities (Bird 1996; Connell 2002; Connell and Messerschmidt 2005; Demetriou 2001; Donaldson 1993), on homophobic practice. Secondly, we argue that even within these spaces, many gay students find strategic ways of navigating their spaces through performances of gender identity, 'invisibilising' of sexual orientation, deliberate avoidance and embracing of particular friendships, and interactions and relations with different people and groups on campus. Some of these strategies are effective in maintaining a sense of wellbeing but can also be argued to be detrimental to challenging the broader status quo. This notion of the performative has been argued by theorists such as (Butler 1990) to be a fundamental aspect of identity management. Data for the study were collected through in-depth individual interviews with gay-identified students (who identified as being 'out of the closet'). We conclude by discussing some of the implications for transformation and destabilisation of heteronormative practice in higher education. 


\section{THEORETICAL OVERVIEW AND CONCEPTUAL FRAMEWORK}

Given the current study's focus and emphasis on heteronormativity as a crucial concept to thinking about normalisation of gendered and sexual practice, we utilised the concept as a means of critically reflecting on and discussing power and difference. In her well-known essay Compulsory heterosexuality and lesbian existence, Adrienne Rich (Rich 1980) first introduced the concept of 'heteronormativity' in which she argues that certain social and institutional practices in society are organised and reinforce particular assumptions of sex and gender. Part of this organisation is the normalisation of heterosexuality and marginalisation of nonheterosexual identities and practice. Heteronormativity as a concept is therefore useful in understanding how different and multiple facets of social, legal, cultural, medical, and educational domains of living are deployed in rendering heterosexuality as normal and other non-conforming gendered practices as abnormal. Part of the heteronormative assumptions is the belief that opposites attract within a binary sexed and gendered lens whereby only men and women exist and are attracted to each other (Kitzinger 2005a, 2005b). Such a belief reinforces the prejudice and violence that characterises many practices of homophobia (Arfer and Eaton 2013; Arndt and De Bruin 2006; Hames 2011; Icard et al. 2015; Lee and LaDousa 2015; Nduna and Mavhandu-Mudzusi 2015; Rich 1980; Schilt and Westbrook 2009).

In our analysis of the data and exploration of heteronormative practice, we have also relied on Connell's concept and theory of hegemonic masculinity (Connell 2002; Connell and Messerschmidt 2005) to understand the gendered form of incidences of homophobic interactions experienced by gay male students in the study. Hegemonic masculinity addresses those aspects of the social and structural elements in society that reinforces and maintains gender hierarchies between women and men as well as between men (Demetriou 2001). The concept has been deployed in understanding gendered relations that not only construct masculinity in a singular and hegemonic way but also how such constructs are in turn used to perpetuate and maintain these relations of power and inequality. The concept has since been applied by researchers to demonstrate intersections of masculinity with other social categories (Christensen and Jensen 2014) to render some forms of masculinity more powerful than others. We would argue that race and class remain important intersections in understanding homophobia within the South African context. In this study especially, the discussion of homophobia and prejudice experienced by black gay male students is telling in how such an intersection of identities are present in practices of heterosexuality and hegemonic masculinity. Other researchers have demonstrated the importance of the concept in influencing and 
reinforcing acts of sexual aggression and homophobic violence against women and men (Buell 2014; Smith, Parrott, Swartout and Tharp 2015).

Finally, in our engagement with interpreting the strategic deployments of identity and performance of sexuality as a means of negotiating safe and unsafe spaces, we have relied on Butler's theory of performativity (Butler 1990, 2011) to understand how gender identity and sexuality may be performed in strategic ways that demonstrate the social constructed nature of gender. More than this, such a theoretical lens allowed for a critical understanding of the role of language in the performance of gender. In this regard, the approach shares some similarity with much discursive psychological work that explores the active role of language in constructing social reality (Kent and Potter 2014). Although largely abstract in argument, Butler’s approach to thinking about gender identity and practice is very useful for understanding both the external performances of gender as social constructs as well as the different ways that individuals may also resist these constructs and norms. This was very useful in analysing and interpreting the different accounts of survival through performance that our participants mentioned.

\section{LITERATURE OVERVIEW}

Much of the research on heteronormative spaces and the university have engaged aspects of attitudes, prejudice and homophobia (Arndt and De Bruin 2006; Holton 2014; Lee 2002; Lee and LaDousa 2015). However, much work still remains to be done on campus residence spaces in particular, as well as other more subtle domains of interaction, such as the curriculum and classroom interactions. International research on this aspect of LGBTI students' experiences has demonstrated important findings that attest to the deeply conservative and hegemonic nature of such spaces (Taulke-Johnson 2010). South African research, though minimal, has equally demonstrated the significant challenges facing many LGBTI students in residences (Jagessar and Msibi 2015) such as experiencing physical violence and other discrimination by other students. It has further been argued that the silencing around these acts of discrimination and aggression have been reinforced via the normalisation of heterosexuality within heteronormative institutional cultures (Jagessar and Msibi 2015). Given the sensitive nature of the issue, much of this research was done through explorative and qualitative methodological approaches. Other research has explored more widely using quantitative methods to determine the attitudes and perceptions of the broader university climate toward LGBTI students (Arndt and De Bruin 2006). It has further been found that many students who experience discrimination and victimisation because of their sexual orientation, often fail to report these 
acts of aggression (Jagessar and Msibi 2015). This is possibly related to the fear of further victimisation as well as the general sense that nothing will come of reporting and drawing attention to oneself. Researchers working in this area have argued that many South African universities remain spaces of exclusion for many LGBTI students (Gibson and Macleod 2012; Graziano 2004, 2005; Msibi 2009). Furthermore, the intersections of race, class, gender and sexuality must be recognised as significant to how homophobia and discrimination within university spaces are experienced for many LGBTI students (Hames 2007).

University accommodation spaces have been shown to be characterised by re-assertion of heterosexual discourses that reinscribe the heterosexual matrix (Butler 2011) with regards to living spaces (Taulke-Johnson 2010). Indeed, within such a space, student diversity must be negotiated and is not a given. Through exploratory action research, issues of isolation and exclusion have been shown to be central to how LGBTI students navigate their environment and different spaces of interaction (Ellis 2009; C. Lee 2002; Peters 2003). And yet, other studies have questioned the dominant narrative discursive account of LGBTI students' experiences wholly in terms of negative experiences (Taulke-Johnson 2008). This research have demonstrated that the emphasis on negative accounts contributes to binary and rigid understandings of LGBTI experiences and identity that are stereotypical in their presentation of only one aspect of lived experience. While we agree with such an assessment, it is also important to recognise the different spaces of interaction and lived experiences within which many LGBTI accounts of homophobia occur. In other words, we should seek to encourage research into positive and other identity-affirming experiences of being LGBTI. At the same time, these accounts must not sweep under the rug the ongoing practices and enactments of heteronormative cultures that exclude all gender non-conforming students. In a context such as South Africa, where homophobia often interfaces with other axis of race, class and gender (Hames 2007, 2011; Mkhize, Bennett, Reddy and Moletsane 2010; Nduna and MavhanduMudzusi 2015), such critical emphasis on the forms of homophobia are important.

\section{RESEARCH METHODOLOGY}

\section{Research design}

A qualitative research design was adopted for the current study. This was deemed the most appropriate design for such as study given the highly sensitive nature of the issue as well as the explorative aspect of the study objectives. The overall objective of the research was to explore how gay male students (who openly identify as gay) experience the residential as well as more 
general spaces of interaction within the university. Qualitative research enables such an exploration given its open-ended nature that allows for subjective accounts and interpretations to emerge in a fluid and open manner (Attride-Stirling 2001; Elo et al. 2014). Exploratory and open-ended individual interviews were conducted with five gay students, focusing on their navigation of social spaces and being gay students in residence. The interviews discussed their experiences as well as their survival strategies in how they responded to moments of discrimination and victimisation. Such a research design also allow for the exploration of the different moments of intersectionality such as race and class in demonstrating how sexuality and gender cannot be understood outside of their interface with other social categories.

\section{Participants and procedure}

Five participant interviews are included in the current analysis. All participants in the study identified as gay at the time of the interviews and were also living openly as gay students in the residences. Participants were between the ages of 18-25 and are categorised as black African. Participants were invited to participate in the study by the researchers through informal and formal invitations. Firstly, poster invites were made available to the broader community inviting students to talk about their experiences of diversity, inclusion and exclusion specific to gender and sexuality. Secondly, more informal type of invitations through snowball sampling were used. This method, garnering participants for such a sensitive topic, has been very useful for small-scale type of research designs (Denscombe 2014). The individual interviews were conducted on campus at a location where participants were comfortable. Participants were informed about the purpose of the study and why they were specifically invited to participate. They were also informed about their right to withdraw at any point in the interviews and were given consent forms to complete. Interviews were conducted by the two researchers (one whom is female and lesbian and the other male and heterosexual). Our perceived differences from the participants (in terms of sexual orientation and gender) are important differences to note and consider when thinking about the researcher dynamics that was established with our participants (another article is being written on these reflections). One of the key concerns raised by potential participants was confidentiality. All the participants were highly worried about their identities being known, and as a result, did not want to be interviewed in their residences, despite being 'out of the closet'. This revealed their fear of reprisals for sharing information about homophobic practices within residences. Pseudonyms are used in the article as well as for residences in order to protect the identity of these students. 


\section{Data analysis}

Individual interviews were recorded and transcribed for detailed discursive analysis based on the work of Wetherell and Edley (1999). Discursive analysis suited the analysis of meanings that the participants made about their lived experiences and strategies of resistance and survival to assert their identities within residences. In the data analysis, we paid particular attention to the feelings and emotions that the participants shared about both their experience of and resistance to victimisation.

\section{FINDINGS AND DISCUSSION}

Three broad themes are discussed in relation to the negotiation of social space and managing one’s sexual identity: 1) harassment based on perceived sexual orientation; 2) residential spaces as enforcing heterosexuality; and 3) survival strategies. These themes are discussed below.

\section{Harassment based on perceived sexual orientation}

All of the students interviewed described accounts and moments of experiencing minor to severe forms of harassment from others based on their perceived sexual orientation. The findings suggest that homophobia and the assertion of heterosexuality occurs in sometimes subtle forms that make it impossible for the recipient of such violence to either respond or report the matter. At other times, this hidden aggression takes place in more direct and violent ways such as deliberate exclusion from social events or particular social spaces to denigratory comments and also physical acts of aggression. In both these instances - both hidden and open aggression - students reported not reporting the incidences for different reasons. Instead, they talked about different strategies that they may tend to adopt as way of counteracting the effects of homophobia. These strategies are discussed in more detail as separate themes.

The encounters with homophobia was often discussed in relation to perceptions of sexual orientation as different from the norm, whereby others perceived, through physical appearance and type of friendships formed, one's sexual orientation. Based on these perceptions, different forms of sexual harassment would ensue, such as name-calling and making sexually suggestive remarks. For example, some of the participants described responses from others thus:

... even when I had straight friends over, people would [say] '... Batho’s boyfriend is here' ... lala la la, stupid things like that, and like I know I had a friend who lived at men's res, [...] like I had a friend who lived at men's res who had another friend over and it was [...] just because he was friends with a gay person, it just became like a huge issue. Oh like yea, 'Batho is bringing his boyfriend over, this isn't, you know hey Batho you gonna take it up the ass', things like, really stupid men's res things [...] agh they so stupid. When I heard that story I was really upset, but those are the kind of things that like I think I tried to avoid Marika, ${ }^{1}$ and I did good with it in the most part. (David, gay student). 
In Res like I would, it would just be like general comments like uhm, what would they? Like It would just be like 'mxm look at him' or whatever but weird like sneered comments like that, ... but those kinds of comments ... were passive, they happened behind my head I didn't mind them. ... But in 2013 that was the year ... things went a notch up, uhm and people like you know would stop me midway, mid-walking stop me and say something really inappropriate or grab me or say let's go here, that's when I realized like the ... level of ... [interrupts himself] ... even like ground staff, who generally like to prefer to be invisible or they themselves feel like marginalised or unseen and therefore don't generally interact with students, even they somehow managed to master up a sense of entitlement a master up a sense of ... power that they knew they had just by virtue of being heterosexual men, that somehow they were entitled, uhm to my body even if it wasn't because they were attracted to it but just by virtue of knowing that uhm they have a power and they could do pretty much with whatever they could with it. I mean I became that object is when I realised like just how pervasive and how ... violent it can be. (Thomas, Gay student).

... in most cases my experience have been good in that part, with regards to students and academics. But there has been incidences on campus with like ground staff, where I would wear like my short shorts and they would be on some 'hey thank you for welcoming to spring' or like 'hey lets go somewhere and like, you know let's put those legs to good use', comments like that, really disgusting [...] like those kinds of comments would be the ones that would be upsetting. But like I never ever experienced like kind of situations from students. (Silas, Gay student).

The above excerpts highlight not only what happens when they are perceived to be nonheterosexual men by other men but also interesting, what happens when such incidences occur. Their responses to these practices of homophobia - being teased, name calling, violation of bodily integrity and so on - echoes what other research demonstrates with regards to silencing (Jagessar and Msibi 2015). Sometimes, this may be because they perceive nothing can be done but also that such practice has become so normalised that it is taken for granted when it does occur (Jagessar and Msibi 2015). The excerpts also highlight the different moments when sexuality, as perceived through physical appearance, comes to define and construct the gay student in binary ways that essentialise identity and behaviour. Part of this construct and essentialising practice is the stereotypical construct of the gay body as exclusively sexed and feminine. Interestingly ideals of hegemonic masculinity are evident in how such a construct is seen to challenge notions of real masculinity and are therefore deemed problematic - such that the gay body must be policed through reference to this feminisation and assumed sexual passivity: 'taking it up the ass', 'let's go somewhere and put those legs to good use', etc.

For David, having a friend over at his room evokes all kinds of imagination of them locking themselves up and having sex, which is considered to be deviant because it is 'up the ass'. The dominant image is that male students cannot think of a gay student having a male friend without equating that to something sexual. Thomas' comment about becoming that 'object' is that the body of a gay male student is reduced to a sexualised entity. Even to the extent that marginalised men who work as cleaners in the residences feel more empowered to 
belittle gay male students by virtue of being heterosexual, despite their own positioning within the hierarchy of the university spaces. All men (male students and male cleaners) were either explicitly or implicitly homophobic, despite their differences in terms of class and educational levels. Their point of unity was their shared dislike or hatred/repulsion of gay male students. It becomes evident that homophobia is not merely making gay men feel like victims but this also serves to maintain certain practices of heteronormative masculine culture in society.

Furthermore, Thomas' account above also illustrates an interesting dynamic in the implied construct of sexual rights and the subjects within this discursive construct. The taken-forgranted assumption of masculine entitlement to the other's body is present but this is an entitlement that only becomes legitimate when the other's body is constructed as 'not masculine'. In other words, only when the feminisation of the gay male body is made possible through naming, discourse, and positioning as different, does it become possible to violate the bodily integrity of the other. It is in this sense that practices and incidences of homophobia cannot be read outside of the broader gendered heteronormative matrix in society that influences how gender relations are constructed and negotiated (Schilt and Westbrook 2009). This includes the influences of a hegemonic masculinity performative to the gendering of behaviour and identities (Connell 2002; Connell and Messerschmidt 2005; Demetriou 2001; Kitzinger 2005a; Msibi 2009).

The exclusionary practices embodied in the sexually suggestive comments and other harassing behaviour described in the excerpts further highlight the role of regulation. This regulation, we argue, is fundamental to hegemonic masculinity enactments. The perceptions of gay bodies not identifying and reproducing the social constructs of a masculine ideal attest not only to the fragility of masculinity (Segal 1990) but also to the social necessity that all men must both identify and regulate their behaviours in relation to this masculine ideal (Demetriou 2001). Bodies perceived to not be in line with such an ideal are ostracised and shamed as part of a regulatory practice. Gay bodies occupying heterosexual space such as male residences on campus are often caught up in such regulatory practices that function to deny any agency in defining and performing gender differently. This regulation extends to heterosexual bodies that seem to accommodate the 'Other'. For example, David's account in the excerpt highlights the disciplining practice that is exerted upon a straight man that seems to be accommodative of sexual difference and that such a male body may automatically be perceived as gay (Langa 2015). This shows how men police each other, even in terms of who they befriend. The harassment that characterises his perceived friendship with a gay student is similar to the disciplining practice that other researchers have argued are part of hegemonic school cultures 
(Nayak and Kehily 2006). Heterosexual masculinity, as these researchers have argued, remains a fragile identity that must be asserted, performed and regulated in rigid ways if it is to maintain its hegemonic status. It is in this regard that Segal (Segal 1990, 123) has observed about masculinity: 'the more it asserts itself, the more it calls itself into question'. Given this fragility, it is not surprising that heteronormative spaces that assert the dominance and legitimacy of heterosexuality within institutions are characterised by such displays and enactments of male aggression and hostility toward gender non-conforming bodies.

\section{Residential spaces as enforcing heterosexuality}

As argued earlier, male residential spaces on campus are functional as sites of performative macho masculinity that legitimates homophobic attitudes and practices. In the participants' accounts this particular function emerged not only in terms of othering gay students but also through the deliberate enforcement of a hyper-masculine culture. The latter is part of a regulatory process that distinguishes types of masculinities and prioritises those that embody a hegemonic heterosexual presentation (Chen 2014; Coupland 2014; Johnston and Kilty 2014). In the excerpt below, David highlights this performance of a macho masculinity as intrinsic to male residential spaces:

... men's res, its macho, its bravado, its entitlement, it's just everything that I've never been comfortable like expressing, because it's not something that I picked up socially, so uhm I've never been able to, like I've always known that like just the kind of ideas, and the kind of identity that that res has, [...] this type of masculine thing, you know just like 'yea we the men on campus, like huh' (imitation with a deep voice). They had a weird slogan a couple of years ago, how was it? It was something about how what animal they are, it's like this is so stupid, this is a very stupid res. And it's so typical of like just being a macho man on campus, and trying to live up to those things. And a lot of people like didn't agree with them, but for some reason they found it easier to conform than I did. (David, Gay student).

However, it is also interesting on how David caricatures the macho behaviour of male students by imitating their deep voice when they say 'we are men on campus'. This further reveals the fragile nature of masculine identity that needs all kinds of slogans by comparing itself with a fearless and brave animal. All these represent the notion of performativity as argued in Butler's (1990) work that performative enactments of masculinity do not just exist at the level of social performance as described in the above excerpt, but also with regards to how gay male students are disciplined within these spaces. In the excerpt below, Sipho recounts his experiences of navigating intimate bathroom spaces and the typical kinds of responses from his peers that attest to this demarcation of space in terms to who is considered a 'real man': 
There are so many times I feel that I do not fit in staying at the res. Many times. Sometimes, I would walk into the shower and people would not want you to be there. They would say names when they pass you and they would say homophobic names and laugh.

Interviewer: You walk into the shower room and they make these remarks about you?

Sipho: Yes. The minute you walk in they all walk out and say these names. Even the House Com, those guys are one of the people that we should report to when things are going wrong in the res, but you find that they also don't accept you, they don't even want you to be there at Men's Res, and they don't even stop the guys when they are doing things like that.

The disciplining practice that occurs in Sipho's attempt to share intimate space with his peers is similar to Johnson and Kilty's (2014) finding that an established code of masculinity exists within dominant and hegemonic spaces whereby anyone falling outside of the norm is 'disciplined' and excluded from the broader social circle. Sipho's account demonstrates the 'micro-aggression' that can also accompany homophobic forms of behaviour in which no direct physical act of aggression is displayed but a form of aggressive conduct, a kind of violence still gets re/enacted toward the gender non-conformist. Two things occur during this process: on the one hand, a form of naming, shaming and disciplining of the gay body is present, and on the other hand, a reassertion of heterosexual masculinity is achieved - in that moment of walking out, walking away from implied 'contamination', a refusal to acknowledge the other's identity as acceptable. However, this may also be analysed as representing the fear of male students to be seen potentially as sexual objects, relying on a stereotypical thinking that gay male students are sexual freaks or predators that one cannot be in the same bathroom as them. Furthermore, this symbolic violent reaction of walking out of the shower also reveals the fear of what this encounter may evoke for male students, possibly their homoerotic feelings and impulses. It is therefore better for them to avoid such an encounter by running out of the shower once a gay student enters. In this encounter, we are left with an image of a male student running for cover with a towel over his private parts. It is the most uncomfortable moment for a male student to be in the same shower with a gay male student.

Given what we now call the 'shower moment', it also became evident in the study that abusive experiences of gay students often get neglected and silenced within residences, including house committees which are expected to play a protective role over all students irrespective of their sexual orientation. The silencing that accompanies such moments of microaggression against gay students in residence extends to different levels of keeping the recipients of such aggression in their place:

we would have House Com meetings and when you ask them to put it on the agenda, they will say that the meeting is only about the important things and not people's personal issues. But I'm learning to manage my interactions and how I relate to people. But it's hard, cos even in terms of 
things that I used to enjoy doing like sports I can't do them anymore; it's hard for them to accommodate me.

Interviewer: Accommodate you in what way?

Sipho: Like I wanted to start a netball team and I spoke to the House Com about it and they said that netball was for girls and sissy boys like me. And that they only play soccer and rugby in Men's Res. And you attend House meetings there would be these remarks to the point where I got so uncomfortable that I ended up no longer attending those meetings.

Interviewer: Homophobic remarks?

Sipho: Yes. So I ended up not attending house meetings. And now they want to start a House Newsletter and as much as I am doing Media and I love it, I didn't sign up for that because I know they are gonna try by all means to make me feel uncomfortable.

Silencing of gay male students happens at different levels in that their voices are suppressed in the public residence meetings as there is anticipation that they may raise personal issues or struggles of homophobia which male students are not prepared to hear or propose sporting codes such as netball, which male students consider to be for sissies. Given all these homophobic experiences, gay students employ various survival strategies as discussed in the subsequent section to avoid, manage and align themselves with student support groups on campus.

\section{SURVIVAL STRATEGIES}

\section{Avoidance}

The participants' accounts of avoidance attests to the avoidance strategy that many gay men fearful of homophobic violence engage in (Almeida, Johnson, Corliss, Molnar and Azrael 2009; Icard et al. 2015; Jacques 2014; Plant, Zielaskowski and Buck 2014; Skinta, Brandrett, Schenk, Wells and Dilley 2013). Strategies of avoidance of avowed physical spaces or social spaces where one's sexuality is considered problematic can be read as a survival strategy that enables the individual to maintain a sense of well-being, both physically and mentally. The psychosocial stress that comes with openly living as an LGBTI individual have been documented as prevalent amongst this population group (Almeida et al. 2009; Meyer 2003). As one of the participants mentioned:

... in the beginning you always had to like hide yourself right, like as a s, well that's just I grew up, as a survival mechanism, I need to hide myself, hide that part of, who I am .... (David, Gay student).

Another participant, Sipho, discusses his response to potential and direct homophobia as primarily one of avoidance: 
... so I have decided not to invade straight black men’s spaces anymore. I just avoid if I can help it now.

Interviewer: Are you aware of other gay students in the res who experience similar kinds of behaviour from the students here?

Sipho: Yes. And I know of people who have experienced even worse things than me. I know this one guy who has even moved out of res. He stayed in Maple ${ }^{2}$ and when it was the time for electing House Reps, there was this guy whose campaign was that he would make sure gay students are not accommodated in that res and that they will be made to leave. And this guy was scared because there were already stories of some attacks on gay students, and so he decided to leave and he is now staying in Braamfontein.

All the excerpts reveal that one of the common avoidance strategies is to render oneself invisible by part of the self that are stereotypically being associated with being a gay, a point we further discuss in the section below. Some avoidance strategies involve not staying in residences which are known for violent homophobic practices. However, there are questions whether avoidance strategies are effective in confronting and destabilisation of heteronormative practices, but for gay male students this is one of the survival strategies available for them as there are no mechanisms and structures within residences to deal with their complaints.

\section{Identity management}

Another survival strategy that the participants discussed included trying to manage their identities as gay men in such a way that their sexuality was not considered threatening or visible. Such tactics attests to the performative nature of gender that includes repetitive behavioural performances as part of identity construction and management. Participants discussed different ways of managing their identities as gay men: on the one hand, there is the process of 'hiding' one's sexuality through deliberate manipulation of physical appearance and behavioural performances:

... sometimes I have feminine gestures and I have to try and overcome that. (David)

I try not to be so obviously gay, even though I am out as a gay man. Lucky for me, I am not readily identifiable. I think they are more accommodating if you are not always in their face, you know. And I know it may seem as a contradiction with me being out and proud, and the like [laughs]. But sometimes it's easier to be in res if you are not such a threat or you are not so open and flamboyant. (Sipho).

Research demonstrates that for many LGBTI individuals the process of identity management remains a significant feature of everyday living and working (Clarke and Smith 2014; King, Mohr, Peddie, Jones and Kendra 2014; McKenna-Buchanan, Munz and Rudnick 2015). For many, the fear of not being 'obvious' in their physical appearance relates to the fear of physical 
safety and fear of homophobia (Clarke and Smith 2014). On the other hand, identity management may also include performances that actively promote one identity over another. This is part of a strategy to assert the importance of other intersecting identities beyond one's sexual orientation:

... so I knew that I needed to be really good at what I'm doing. And so uhm it was through like engaging in class and like making my opinions known and making sure that my opinions were valuable and worth saying, that like put me in a position where suddenly everybody else was coming to me for help with their school work or anything like that. And that in itself allows me, allows like my academic excellence to kind of like outshine any kind of like stigma that is attached to LGBTI uhm communities and whatever. So that's always been how I've navigated my sexuality and sexual orientation, it's just like to be brilliant (raises voice) so that people suddenly, it becomes an afterthought, 'oh but he's not straight', so that's how I've always like negotiated it, and I think I’ve been doing a good job thus far .... (Silas).

Actively promoting this academic identity is necessary to a kind of impression management (King et al. 2014) that is part of negotiating sexual identity within heterosexual spaces. For Silas, an academic identity is central to his strategic self-positioning as 'more than gay' and he deploys this identity in deliberate ways that function to diminish the emphasis on his sexuality by others. It is through his academic excellence that he exerts his power over others. The stigma of being gay temporarily disappears, but for others is afterthought 'oh ... he is not straight'. Here it seems the stigma remains inescapable despite one's intellectual prowess. In his account, Silas is able to recognise this as a kind of identity 'performance':

I always try to like, even if I don't have it at the time, I try to like express or uh what's the other word? Like perform my confidence. So like, even if I'm like feeling like the most insecure person on the, that's when I like step it up, like here I am, this is what I know, this is what I can do and I allow that to almost like distract people, distract people from anything else that like they might use as a weakness, might use against me and I don't even think that my sexual orientation can be used against me but just in case. (Silas).

The identity management strategy seems to be working for Silas, although this sounds costly as he needs to be conscious of the self in managing and performing his confidence so that it distracts anyone of seeing his sexuality.

\section{Finding (and avoiding) allies}

Another significant theme emerging from the interviews concerned the role of support networks on campus as a strategy for dealing with homophobia and a general sense of isolation. The strategy of aligning oneself with social groups on campus or forming friendships with other LGBTI students was on the one hand considered to be necessary to one's survival as gay 
student. Yet, on the other hand, it was also constructed as a potentially 'visibilising' strategy that rendered one even more vulnerable to hostility and aggression. Participants described mixed experiences and feelings about the LGBTI student group on campus thus:

... I think it's because I needed to be a victim first for me to realise the importance of like the LGBI student group on campus. (Thomas).

Choosing to join ACTIVATE ${ }^{3}$ for me was a necessary choice because at the end of the day you want to be with people you can share your identity with. It was too lonely for me otherwise. (Sipho).

I joined ACTIVATE but I have to say it was a huge disappointment for me. I thought I would get that support that I needed as a gay man, but that was not what they were really about. To them it's about going out, finding you a boyfriend or girlfriend, like hooking people up with the chatrooms and stuff. I thought a society like that had to ... I thought they would be involved in getting speakers and activists, people that are going to talk to you about living as a gay person in society and on campus. (Mandla).

Some students realised the importance of joining LGBTI groups after their victimisation. LGBTI groups provided a safe space for these students to freely express their identity, while others spoke about the potential vulnerability that comes with aligning oneself with an LGBTI student group on campus. Being caught between seeking psychosocial support while simultaneously making oneself open to further homophobia through such networks, was a fine line that students had to negotiate as part of their coping strategy. However, for some students (e.g. Mandla) joining a LGBTI group was such a disappointment as this group was preoccupied about parties and hooking individuals up with potential partners, reinforcing existing stereotypes that being a gay is all about sex and nothing else. Mandla's view was that LGBTI groups need to be more active in dealing with homophobia in residences and other spaces within the university. These students, as shown in the extract below, were critical about their belonging to LGBTI student groups as their identities were reduced and essentialised to their sexual orientation.

... it wasn't even like I think out of shame or self-loathing or anything like that, it was just a matter of like maybe I understood the vulnerability that they experienced and I knew that like it wouldn't be helpful for me at the time to be able to be like get to where I wanted to be without like carrying that label as the first thing that people think of as me. And that was like with some of my big reservations about uhm joining Activate as well, is that like it positions me like, in that it makes me or it makes my sexuality or sexual orientation the foremost thing that people think about. And I mean it's a significant part of who I am but like I don't want it to be seen as a foremost thing. (Silas).

Silas’ excerpt above further highlights an interesting privilege that many LGBTI-identified people do not enjoy in the same way as heterosexuals - that sexuality comes to be the first 
defining marker of identity when people look at them. Their identities simply diminish and get overshadowed, which is not the case with heterosexual men. This recognition of double standards is evident in Silas' observation:

... having that identity overshadow everything else, because it's not the case with straight people, you don't like see their straightness as the first thing that you see, you see them as thinkers, you see them as interesting, you see them as mysterious or whatever, you will see them as weird, arrogant, jerks but you won't ever like say 'oh there's a straight person, wow he's straight but he can, he's so eloquent or whatever'. So that's what I've, that's what I've, that's how I've always tried to negotiate my sexuality and sexual orientation. (Silas).

Although LGBTI student groups offer support on campus, despite some reservations, the struggle for gay male students continues to be a daily routine that they need to negotiate and manage. What is clear is that the isolation and exclusion that many LGBTI students experience within institutions and within residences, in particular contribute to emotional and psychosocial stress that must be addressed as part of the transformation agenda in higher education. It is clear in this article that university residences are characterised by many incidents of harassment and violence which are often silenced, ignored and swept under the rug by victims due to lack of egalitarian and tolerant spaces with universities to address all these abuses.

\section{CONCLUSION}

This study has explored the subjective experiences of a group of gay male students living in residences on the university campus. Clearly, much more work needs to be done on understanding the contexts, nuances and cultures within student residences that exclude LGBTI students, and in what ways. This study has contributed to some of these issues by focusing on the accounts of a group of gay students living in residence at an institution of higher learning. We discussed the three broad emerging themes from the interviews that demonstrated students' strategies of coping as well as their desire for recognition beyond sexual identity. The findings also highlighted the harassment that these students experienced, such as name calling and violation of bodily integrity. We argue that the theoretical tools of performative theory, hegemonic masculinity and heteronormativity as concepts are useful in providing an understanding of the different performances of gender and sexuality by both LGBTI and heterosexual individuals. This constructed nature of gender and sexuality has deep implications for how we may begin to think of challenging gender norms.

\section{NOTES}

1. Changed the name of the residence to protect the identity of the participant. 
2. All-Male residence which is known for homophobic practices against gay students.

3. LGBTI Student Group on campus.

\section{REFERENCES}

Almeida, J., R. M. Johnson, H. L. Corliss, B. E. Molnar and D. Azrael. 2009. Emotional distress among LGBT youth: The influence of perceived discrimination based on sexual orientation. Journal of Youth and Adolescence 38(7): 1001-1014.

Arfer, K. B. and N. R. Eaton. 2013. The organization of sexual preferences. http://arfer.net/projects/ galaxy/paper (accessed 9 July 2015).

Arndt, M. and G. de Bruin. 2006. Attitudes toward lesbians and gay men: Relations with gender, race and religion among university students. Psychology in Society 33: 16-30.

Attride-Stirling, J. 2001. Thematic networks: An analytic tool for qualitative research. Qualitative Research 1(3): 385-405.

Bird, S. R. 1996. Welcome to the men's club. Homosociality and the maintenance of hegemonic masculinity. Gender \& Society 10(2): 120-132.

Buell, K. 2014. 'Get off me bro!': A discussion of the gay panic defense, it’s place in the courtroom, and it's intersections with hegemonic masculinity. http://repository.uwyo.edu/ugrd/2012_UGRD/ Presentations/9/ (accessed 9 July 2015).

Butler, J. 1990. Feminism and the subversion of identity. New York: Roudledge.

Butler, J. 2011. Bodies that matter: On the discursive limits of sex. Taylor \& Francis.

Chen, C. H. 2014. Prioritizing hyper-masculinity in the pacific region. Culture, Society and Masculinities 6(1): 69.

Christensen, A.-D. and S. Q. Jensen. 2014. Combining hegemonic masculinity and intersectionality. NORMA: International Journal for Masculinity Studies 9(1): 60-75.

Clarke, V. and M. Smith. 2014. 'Not hiding, not shouting, just me': Gay men negotiate their visual identities. Journal of Homosexuality 62(1): 4-32. doi: 10.1080/00918369.2014.957119

Connell, R. W. 2002. On hegemonic masculinity and violence response to Jefferson and Hall. Theoretical Criminology 6(1): 89-99.

Connell, R. W. and J. W. Messerschmidt. 2005. Hegemonic masculinity rethinking the concept. Gender \& Society 19(6): 829-859.

Coupland, C. 2014. Organizing masculine bodies in rugby league football: Groomed to fail. Organization. dx.doi.org/10.1177/1350508413517409

Demetriou, D. Z. 2001. Connell's concept of hegemonic masculinity: A critique. Theory and Society 30(3): 337-361.

Denscombe, M. 2014. The good research guide: For small-scale social research projects: McGrawHill Education (UK).

Donaldson, M. 1993. What is hegemonic masculinity? Theory and Society 22(5): 643-657.

Ellis, S. J. 2009. Diversity and inclusivity at university: A survey of the experiences of lesbian, gay, bisexual and trans (LGBT) students in the UK. Higher Education 57(6): 723-739.

Elo, S., M. Kääriäinen, O. Kanste, T. Pölkki, K. Utriainen H. Kyngäs. 2014. Qualitative content analysis. SAGE Open 4(1). DOI: 10.1177/2158244014522633

Gibson, A. and C. Macleod. 2012. (Dis)allowances of lesbians' sexual identities: Lesbian identity construction in racialised, classed, familial, and institutional spaces. Feminism \& Psychology. DOI: $10.1177 / 0959353512459580$

Graziano, K. J. 2004. Coming out on a South African university campus: Adaptations of gay men and lesbians. Society in Transition 35(2): 273-286. 
Graziano, K. J. 2005. Reflections from university students in a South African gay and lesbian society. International Journal for the Advancement of Counselling 27(2): 299-310.

Hames, M. 2007. Sexual identity and transformation at a South African university. Social Dynamics 33(1): 52-77.

Hames, M. 2011. Violence against black lesbians: Minding our language. Agenda 25(4): 87-91.

Holton, M. 2016. The geographies of UK university halls of residence: Examining students' embodiment of social capital. Children's Geographies 14(1): 63-76.

Icard, L. D., J. B. Jemmott III, G. Barnes, T. Mayekiso, Z. Ngwane, A. O'leary and G. A. Heeren. 2015. Our village is watching: Sociocultural and attitudinal factors related to HIV sexual risk behaviors among black South African men who have sex with men. Journal of Black Sexuality and Relationships 1(4): 85-105.

Jacques, G. 2014. 'Coming out' or coming in? Social exclusion of sexual minorities in Africa: Challenges for social work education and practice. Journal of Gay \& Lesbian Social Services 26(1): 91-110. doi: 10.1080/10538720.2013.829396

Jagessar, V. and T. Msibi. 2015. 'It's not that bad': Homophobia in the residences of a university in KwaZulu-Natal, Durban, South Africa. Agenda 29(1): 63-73.

Johnston, M. S. and J. M. Kilty. 2014. You gotta kick ass a little harder than that the subordination of feminine, masculine, and queer identities by private security in a hospital setting. Men and Masculinities. DOI: 10.1177/1097184X14549998

Kent, A. and J. Potter. 2014. Discursive social psychology 19. The Oxford handbook of language and social psychology, 295.

King, E. B., J. J. Mohr, C. I. Peddie, K. P. Jones and M. Kendra. 2014. Predictors of identity management an exploratory experience-sampling study of lesbian, gay, and bisexual workers. Journal of Management. DOI: 10.1177/0149206314539350

Kitzinger, C. 2005a. Heteronormativity in action: Reproducing the heterosexual nuclear family in afterhours medical calls. Social Problems - New York 52(4): 477.

Kitzinger, C. 2005b. 'Speaking as a heterosexual': (How) Does sexuality matter for talk-in-interaction? Research on Language and Social Interaction 38(3): 221-265.

Langa, M. 2015. 'A boy cannot marry another boy': Adolescent boys' talk about 'gay' boys at school. Journal of Psychology in Africa 25(4): 313-319.

Lee, C. 2002. The impact of belonging to a high school gay/straight alliance. The High School Journal 85(3): 13-26.

Lee, E. M. and C. LaDousa. 2015. Being 'the gay' on campus. In College Students' Experiences of Power and Marginality: Sharing Spaces and Negotiating Differences, 169.

McKenna-Buchanan, T., S. Munz and J. Rudnick. 2015. To be or not to be out in the classroom: Exploring communication privacy management strategies of lesbian, gay, and queer college teachers. Communication Education: 1-21. doi: 10.1080/03634523.2015.1014385

Meyer, I. H. 2003. Prejudice, social stress, and mental health in lesbian, gay, and bisexual populations: Conceptual issues and research evidence. Psychological Bulletin 129(5): 674-697. doi: 10.1037/0033-2909.129.5.674

Mkhize, N., J. Bennett, V. Reddy and R. Moletsane. 2010. The country we want to live in: Hate crimes and homophobia in the lives of black lesbian South Africans. HSRC Press.

Msibi, T. 2009. Not crossing the line: Masculinities and homophobic violence in South Africa. Agenda 23(80): 50-54.

Msibi, T. 2013. Queering transformation in higher education. Perspectives in Education 31(2): 65-73.

Nayak, A. and M. J. Kehily. 2006. Gender undone: Subversion, regulation and embodiment in the work of Judith Butler. British Journal of Sociology of Education 27(4): 459-472. doi: 10.1080/01425690600803038 
Nduna, M. and A. Mavhandu-Mudzusi. 2015. Gay students still not welcome at South African universities. https://theconversation.com/gay-students-still-not-welcome-at-south-africanuniversities-42778 (accessed 24 June 2015).

Peters, A. 2003. Isolation or inclusion: Creating safe spaces for lesbian and gay youth. Families in Society: The Journal of Contemporary Social Services 84(3): 331-337.

Plant, E. A., K. Zielaskowski and D. M. Buck. 2014. Mating motives and concerns about being misidentified as gay or lesbian implications for the avoidance and derogation of sexual minorities. Personality and Social Psychology Bulletin. DOI: 10.1177/0146167214521467

Rich, A. 1988. Compulsory heterosexuality and lesbian existence. Signs: 631-660.

Schilt, K. and L. Westbrook. 2009. Doing gender, doing heteronormativity 'gender normals', transgender people, and the social maintenance of heterosexuality. Gender \& Society 23(4): 440464.

Segal, L. 1990. Slow motion: Changing masculinities, changing men. Rutgers University Press.

Skinta, M. D., B. D. Brandrett, W. C. Schenk, G. Wells and K. W. Dilley. 2013. Shame, self-acceptance and disclosure in the lives of gay men living with HIV: An interpretative phenomenological analysis approach. Psychology \& Health 29(5): 583-597. doi: 10.1080/08870446.2013.871283

Smith, R. M., D. J. Parrott, K. M. Swartout and A. T. Tharp. 2015. Deconstructing hegemonic masculinity: The roles of antifemininity, subordination to women, and sexual dominance in men's perpetration of sexual aggression. Psychology of Men \& Masculinity 16(2): 160.

Taulke-Johnson, R. 2008. Moving beyond homophobia, harassment and intolerance: Gay male university students' alternative narratives. Discourse: Studies in the Cultural Politics of Education 29(1): 121-133.

Taulke-Johnson, R. 2010. Assertion, regulation and consent: gay students, straight flatmates, and the (hetero) sexualisation of university accommodation space. Gender and Education 22(4): 401-417.

Wetherell, Margaret and Nigel Edley. 1999. 'Negotiating hegemonic masculinity: Imaginary positions and psycho-discursive practices.’ Feminism \& Psychology 9(3): 335-356. 